\title{
Formação dos professores para as modalidades educação especial e educação indígena: espaços intersticiais
}

\author{
Teacher's formation for education special and indigene education modalities: \\ interstitial spaces
}

\section{La formación docente para las modalidades educación especial y educación indígena: espacios intersticiales}

JoÃo HENRIQUE DA SILVA*

MARILDA MORAES GARCIA BRUNO**

\begin{abstract}
$\diamond$
RESUMO

Este relato de pesquisa discute a formação de professores para o Atendimento Educacional Especializado (AEE) na interface com a educação escolar indígena. Participaram do estudo quatro professores do AEE em escolas indígenas de Dourados (MS). O objetivo geral foi desenvolver, em conjunto com esses professores, um programa de formação continuada para investigar as ações pedagógicas presentes nas Salas de Recursos Multifuncionais (SRMs) e analisar os impasses, os obstáculos e os desafios do AEE e da inclusão escolar. Fundamentou-se nos estudos culturais a na pesquisa colaborativa, fazendo uso de entrevista semiestruturada, entrevista coletiva e diário de campo. Os resultados evidenciaram: a necessidade de formação inicial/continuada para professores do AEE, adequadas às especificidades das escolas indígenas; a política de formação dos professores como desafio para a superação das práticas hegemônicas e o trânsito entre diferentes espaços intersticiais e fronteiras dos conhecimentos; a emergência da (re)significação do AEE numa perspectiva intercultural e de exercício crítico do fazer pedagógico.
\end{abstract}

Palavras-chave: Formação de professores. Educação especial. Educação indígena.

\section{AbSTRact}

This report of research discuss teacher's formation for Educational Specialized Attendance (ESA) in the interface with indigene school education. Four teachers participated of ESA in indigene school in Dourados (Mato Grosso do $\mathrm{Sul} /$ Brazil). The general objective was develop, in conjunct with those teachers, a program of continued formation to investigate in pedagogical actions presented in Multifunctional Resources Classrooms (MRC) and analyze impasses, obstacles and challenges of ESA and school inclusion. It was based on cultural studies and collaborative research, using semi-structured interview, collective interview and camp diary. The results shown: necessity of initial/continued formation for teachers of ESA, which are adequate to specialties of indigene schools; politic of teacher's formation has as challenge the overcoming of hegemonic practices and traffic among interstitial spaces and knowledge frontiers; emergency of (re)signification of ESA in the intercultural perspective and critic exercise of pedagogical practice.

Keywords: Teacher's formation. Special education. Indigene education.

\section{RESUMEN}

Este informe de investigación analiza la formación de los profesores para el Atendimiento Educacional Especializado (AEE) en relación a la educación indígena. Los participantes del estudio fueron cuatro maestros de las escuelas indias AEE de Dourados (Mato Grosso do Sul). El objetivo general fue desarrollar, en conjunto con estos maestros, un programa de educación continua para investigar las acciones pedagógicas presentes en las Salas de Recursos Multifuncionales (SRM) y analizar las dificultades, los obstáculos y los desafíos del AEE y de la inclusión escolar. Se basó en los estudios culturales y en la investigación colaborativa, haciendo uso de las entrevistas semiestructuradas, conferencias de prensa colectivas y diario de campo. Los resultados mostraron: la necesidad de educación inicial/ continua para los profesores de la AEE, adecuadas a las particularidades de las escuelas indígenas; la política de la formación de los profesores tiene el reto de superar las prácticas hegemónicas y el tránsito entre diferentes espacios intersticiales y fronteras del conocimiento; la emergencia de (re)significación del AEE en una perspectiva intercultural y ejercicio crítico de la pedagógica.

Palabras clave: Formación de profesores. Educación especial. Educación indígena.

\footnotetext{
*Mestre em Educação pela Universidade Federal da Grande Dourados (UFGD). Doutorando em Educação Especial pela UFSCar. E-mail: <jhsilvamg@ icloud.com>.

** Doutora em Ensino da Educação Brasileira pela Universidade Estadual Paulista - Júlio de Mesquita Filho (Unesp). Docente do Programa de Pós-Graduação em Educação da UFGD.E-mail: < marildabruno@ufgd.edu.br>.
} 


\section{INTRODUÇÃO}

No presente texto, discute-se a formação inicial e continuada dos professores que atuam no Atendimento Educacional Especializado (AEE) em escolas da Terra Indígena de Dourados (TID), localizadas no município de Dourados, no estado de Mato Grosso do Sul (MS). Essa temática envolveu duas modalidades de educação: a Educação Especial e a Educação Escolar Indígena. Ambas as modalidades constituem campos de conhecimentos distintos, mas possíveis de serem conciliados e traduzidos culturalmente para a implementação de uma nova configuração no cenário político de formação docente.

Como pondera Laclau (2011), a política da formação de professores para as diferenças não é um processo tranquilo, envolve tensões, disputas de poder e requer negociações. Na construção e efetivação dessa política, as identidades dos professores e a sua profissionalização para atender às diferenças entram em conflito com as identidades universalistas ou particulares, principalmente quando se fala da interface entre as modalidades analisadas.

Na pesquisa de Silva (2014), constatou-se que a política de formação de professores indígenas tem incorporado os modelos da política de formação da Educação Especial. Não houve diálogo, nem articulação com os princípios e diretrizes da Educação Escolar Indígena. Esses fatos interferem no perfil e nas identidades dos docentes do AEE em escolas indígenas de Dourados (MS).

Inicialmente, apresenta-se o referencial teórico e metodológico da pesquisa. Depois, discutem-se os dados relacionados ao perfil da formação desses professores, bem como suas percepções sobre os cargos que ocupam e sobre as condições em que os professores participaram da formação continuada. Os dados apresentados instigam uma revisão das políticas de formação docente e condições de trabalho no AEE em contextos diferenciados socioculturalmente.

\section{Delineamento TEÓRICO-METODOLÓGICO}

O cenário da pesquisa constituiu-se das quatro salas de recursos existentes nas escolas presentes na Terra Indígena de Dourados (TID), que abrange duas aldeias, Jaguapiru e Bororó, localizadas no município de Dourados (MS). À maioria dos habitantes pertence a etnia guaranikaiowá. Esse estudo compôs o macroprojeto denominado "Mapeamento de deficiências na população indígena na região da Grande Dourados/MS: um estudo sobre os impactos e as possíveis implicações para a inclusão educacional", apoiado pela Capes/Proesp e coordenado pela orientadora desta pesquisa.
No decorrer do ano de 2013, desenvolveu-se, em conjunto com os professores ${ }^{1}$ que atuam no AEE, das escolas indígenas de Dourados (MS), um Programa de Formação Continuada. Destinado este a investigar as ações pedagógicas nas Salas de Recursos Multifuncionais (SRMs), avaliando os impasses, os obstáculos e os desafios para a inclusão escolar.

Para analisar a formação dos professores para o AEE no locus das escolas indígenas, o presente estudo se fundamentou na área da socioantropologia, com ênfase nos Estudos Culturais. A Educação Especial no contexto da educação diferenciada indígena constitui-se num novo campo de estudos assentado em políticas culturais, como defendem os autores: Bhabha (1998), Bauman (2005), Hall (2003/2006), García Canclini (2008), Geertz (2001/2008), Laclau (2011) e Walsh (2009).

Foram utilizados alguns conceitos essenciais para subsidiar as discussões, como cultura, "entre-lugar", hibridação intercultural, identidades e tradução cultural. Estes ajudam a compreender que o ser humano é tecido por relações sociais, através das quais constitui sua identidade. Ele transita entre diferentes fronteiras sociais e culturais, o que instiga a traduzir-se culturalmente para operar nos interstícios sociais.

Os conceitos apresentados anunciaram que a formação de professores do AEE para as escolas indígenas necessita ter como ponto de partida as culturas e os significados construídos sobre a deficiência na etnia guarani-kaiowá, uma vez que a cultura contém os significados do grupo. Revelam ainda que a situação das crianças com deficiência nas escolas indígenas e a formação dos profissionais encontram-se em espaços intersticiais, nos entre-lugares. A atuação dos professores do AEE dessas escolas requer traduzir culturalmente as diferentes experiências de vida, e a hibridação cultural entre estes incentiva a negociação dos saberes e das novas identidades.

Quanto ao delineamento metodológico, trata-se de uma pesquisa colaborativa (IBIAPINA, 2008), de abordagem qualitativa e com observação participante, organizada em duas etapas. A primeira partiu da revisão bibliográfica, do estudo documental e dos contatos iniciais com as escolas e com a comunidade. A segunda etapa caracterizou-se pela pesquisa de campo, pelos registros dos dados no Diário de Campo e pela entrevista coletiva no decorrer do ciclo de formação -composto por 14 encontros, dos quais os dois primeiros foram para levantamento de temáticas prioritárias, organização e planejamento dos encontros. Em outros dois encontros, foram apresentados e discutidos os resultados das

\footnotetext{
${ }^{1}$ Identificadas como P1, P2, P3, P4. Todas são mulheres que tinham contato entre si, uma vez que frequentavam os cursos de formação continuada oferecidos pela Semed.
} 
pesquisas (cinco) realizadas sobre o acesso e sobre a escolarização de crianças indígenas com deficiência na região da Grande Dourados. Os demais encontros, num total de dez, versaram sobre os seguintes temas: aspectos normativos e pedagógicos do AEE, princípios da educação escolar indígena, organização, planejamento e funcionamento do AEE, práticas pedagógicas no AEE para as crianças com deficiência intelectual, física, auditiva e visual.

Desse modo, o programa de formação oportunizou um espaço de formação e de reflexão sobre a prática pedagógica dos professores por meio do ciclo colaborativo. Este foi organizado da seguinte forma: a) sensibilização dos colaboradores através do estudo sistemático sobre os princípios da pesquisa colaborativa; b) diagnóstico das necessidades dos professores e elaboração de um plano de ação capaz de atender às expectativas dos docentes.

A proposta, então, foi de repensar o modelo do AEE para as escolas indígenas, à luz dos teóricos e estudiosos da temática da Educação Especial e da Educação Escolar Indígena. Os encontros desse programa também permitiram dialogar com as especificidades da cultura indígena, investigando como aconteceu a formação acadêmica dos professores dessas salas. Ao mesmo tempo, possibilitaram conhecer o amadurecimento profissional através da formação continuada proposta por esta pesquisa.

Ademais, para a análise dos dados da pesquisa, utilizou-se o recurso da triangulação, que tem como objetivo analisar, comparar e contradizer as informações obtidas pelas diferentes técnicas. Esse recurso também contempla o exame da revisão da literatura e o estudo documental e os múltiplos pontos de vista dos professores.

\section{Perfil de FORMAÇÃo dos PROFESSORES DO AEE}

A configuração da formação de professores indígenas para o AEE é atual na política educacional brasileira. Somente a partir do Parecer no 13/2012 é que se nota a sua ausência nas comunidades indígenas. Cabe ao poder público elaborar diretrizes políticas para essa situação. Enquanto isso não ocorre, as Secretarias Municipais de Educação são obrigadas a trabalhar a partir das orientações da modalidade geral da Educação Especial, contrapondo-se aos princípios de autonomia escolar e às características de uma escola indígena diferenciada, específica, bi/multilíngue, comunitária e intercultural (BRASIL, 1998).

Portanto, a interface entre as modalidades de Educação Especial e de Educação Indígena está em processo de construção. Sua menção foi feita, pela primeira vez, pela Política Nacional da Educação Especial (PNEE). A interface tem o objetivo de "[...] assegurar que os recursos, serviços e atendimentos educacionais especializados estejam presentes nos projetos pedagógicos construídos com base nas diferenças socioculturais desses grupos" (BRASIL, 2008, p. 22-23). Contudo, não são possíveis na PNEE orientações efetivas e condizentes com a realidade indígena.

As novas Diretrizes Curriculares Nacionais para a Educação Escolar Indígena na Educação Básica (Res. $\mathrm{n}$ - 5/2012) garantem o AEE para as escolas indígenas, mas na forma de reprodução do modelo não indígena. Ao mesmo tempo, afirmam que o MEC irá elaborar uma política nacional de atendimento aos estudantes indígenas que necessitem de AEE.

A partir da coleta dos dados, verificou-se que o perfil e a formação de professores do AEE da TID são diferenciados. O primeiro fato preocupante corresponde à situação de que apenas $50 \%$ dos professores do AEE são indígenas (P1 e P2). Isto constitui um desafio da política educacional no sentido de formar os professores indígenas da sua própria comunidade para atuar na Educação Especial.

Identificou-se que as professoras P1, P2 e P4 são efetivas e remanejadas para o AEE, porque estão lotadas em outra função da educação básica. Não houve até o presente momento um concurso específico para professor do AEE no município de Dourados. Essa circunstância dificulta uma política de valorização permanente desse profissional no referido município.

Quanto à formação inicial, observou-se que das quatro professoras entrevistadas, apenas uma possui Pedagogia, duas têm licenciatura em Educação Física (uma delas é formada como bacharel em Letras/Libras) e outra é formada em Normal Superior. Quanto à disciplina de Educação Especial, somente a P3 disse que não cursou a graduação.

Assim, as formações desses professores do AEE das escolas indígenas refletem a conjuntura nacional, na qual o processo de formação de educadores para o atendimento especializado não se efetuou de maneira progressiva e continuada. Estudos de Queiroz Júnior (2010), Milanesi (2012) e Nozu (2013) relatam que a política de formação de professores para a Educação Especial é limitada e insuficiente para a consolidação de uma escola inclusiva com qualidade. $\mathrm{O}$ investimento nessa modalidade iniciou-se a partir dos programas de formação ofertados pelo MEC a partir de 2007.

Os pesquisadores acima informam que a formação do docente para o AEE é generalista, diversificada e vaga. Isto se observa no perfil das professoras das escolas indígenas, porque todas tiveram sua qualificação para atuar no AEE por meio da formação continuada em serviço. A P1 foi a única que fez a especialização em 
AEE ofertada pelo MEC, através do Programa Rede de Formação Continuada de Professores na Educação Especial no âmbito do Sistema Universidade Aberta do Brasil - UAB. Essa especialização foi pensada para o professor do AEE atender a todas as deficiências do público alvo da Educação Especial. Ao passo que a P2, a P3 e a P4 participaram de um curso de formação de professores para o AEE em escolas indígenas, sob a supervisão da Semed, e de aulas ministradas pela P1.

Inclusive, a P2 e a P4 fizeram especialização em Libras, a qual lhes qualificou para trabalhar como professoras intérpretes. A P3 fez especialização em Educação Inclusiva. Apenas a P4 possui uma pósgraduação strictu sensu em Educação.

Todas as quatro professoras participam da formação continuada dirigida pela Semed. Relatam que essa secretaria vem desenvolvendo um trabalho em consonância com as expectativas das mesmas. A partir de 2013, foi definida a formação continuada pelos próprios professores do AEE do município. No entanto, as professoras advertem que esses encontros não dialogam com as diretrizes de uma educação escolar indígena. Faltam cursos que abordem as reais necessidades das suas escolas, uma vez que as temáticas propostas partem das demandas das escolas municipais urbanas. Em razão disso, elas afirmam que os professores do AEE das escolas indígenas precisam ter discussões frequentes em conjunto.

De acordo com Nóvoa, a troca de experiência e a partilha de saberes entre os professores "[...] consolidam espaços de formação mútua, nos quais cada professor é chamado a desempenhar, simultaneamente, o papel de formador e de formado" (1997, p. 26). O diálogo entre os professores é "[...] fundamental para consolidar saberes emergentes da prática profissional” (NÓVOA, 1997, p. 26). Por isso, as professoras acreditam que a formação continuada, proposta por esta pesquisa, poderá colaborar com a discussão e com a criação de estratégias para atender as crianças indígenas com deficiência.

Ressalta-se que a formação continuada do professor precisa se pautar nas demandas e nos projetos políticospedagógicos das escolas indígenas. As formações das interlocutoras desta pesquisa, tanto no âmbito inicial quanto continuado, não correspondem aos princípios $\mathrm{e}$ projetos das escolas indígenas. A formação dos docentes requer aproximação das expectativas sociocomunitárias dos guarani-kaiowá. Estas contemplam a participação das famílias, dos alunos, dos professores e da comunidade. Mas ressalva-se que, como reflete Jesus e Effgen, "[...] a formação docente qualificada pode muito, mas não pode tudo. Há que se pensar em outros aspectos macro que configuram os sistemas de ensino e as condições de trabalho docente" (2012, p. 21, grifos das autoras).
Aliás, compreende-se que a formação dos professores do AEE está comprometida também porque sua habilitação em Educação Especial nos cursos de Licenciatura em Pedagogia foi retirada no cenário educacional pela Resolução no 1/2006, em seu art. 10 (CNE/CP). A partir desta, a Licenciatura em Pedagogia passou a formar professores para "[...] exercerem funções de magistério na Educação Infantil e nos anos iniciais do Ensino Fundamental, nos cursos de Ensino Médio, na modalidade Normal, de Educação Profissional na área de serviços e apoio escolar e em outras áreas [...]" (BRASIL, 2006, art. 4ํ). $\mathrm{Na}$ interface da Educação Especial com a Educação Escolar Indígena, torna-se ainda mais emblemático.

Como já foi mencionado, não há diretrizes específicas para a formação de professores indígenas para o AEE, como se pode ver no Parecer no 13/2012, Res. no 5/2012, Referenciais para a Formação de Professores Indígenas RFPI (BRASIL, 2002) e Referencial Curricular Nacional para Escolas Indígenas - RCNEI (BRASIL, 1998). Um silêncio dessa interface está presente nesses dois últimos documentos.

Conclui-se, então, que os professores do AEE das escolas indígenas estão numa conjectura em que precisam aprender a transitar entre as fronteiras das duas modalidades (Educação Especial e Educação Indígena) e traduzi-las para a sua cultura, negociando os saberes e constituindo a sua identidade conforme suas escolhas.

Bauman (2005, p. 54) compara a identidade com as peças de um quebra-cabeça incompleto. A construção da identidade é como uma bricolagem. Trata-se de uma tarefa que envolve toda uma vida e leva o ser humano a se libertar da "[...] inércia dos costumes tradicionais, das autoridades imutáveis, das rotinas preestabelecidas e das verdades inquestionáveis" (BAUMAN, 2005, p. 56).

Nesse sentido, as interlocutoras desta pesquisa deveriam ter a liberdade de construir as suas identidades nos espaços intersticiais de sua formação. Em razão disso, a política educacional precisa repensar formas de implementação de programas de formação para professores indígenas capazes de atender às demandas das crianças indígenas com deficiência. Pesquisas evidenciaram limites na formação dos professores que atuam em escolas indígenas, tais como as de Costa de Sousa (2013), Lima (2013) e Silva Souza (2011). Essas dificuldades advêm da ausência de diretrizes para formação de professores indígenas que, por sua vez, lecionam para crianças com diferentes deficiências. Entre estas, a maior incidência corresponde à surdez, à paralisia cerebral e à deficiência intelectual.

Dessa forma, argumenta-se que a formação de professores para o AEE nas escolas indígenas é imprescindível para garantir um atendimento educacional adequado e com qualidade às crianças indígenas com deficiência. 
Também é fundamental para incentivar a criação de uma cultura escolar diferenciada, específica, multilíngue, que contemple as necessidades específicas dos indígenas com deficiência. Para tanto, faz-se essencial a tradução cultural capaz de construir uma formação acadêmica adequada aos professores indígenas.

\section{A PERCEPÇÃO DAS PROFESSORAS DO AEE SOBRE A EXPERIÊNCIA E EXERCÍCIO DA DOCÊNCIA}

Verificou-se que o tempo de serviço das professoras na área da Educação Especial é diverso. A P1 trabalha há quase três anos como intérprete e três anos na sala de recursos; a P2 atua há quase cinco anos como intérprete e dois anos como professora do AEE; e a P3 está no terceiro ano de trabalho consecutivo no AEE. Ela possui experiência anterior em Associação de Pais e Amigos dos Excepcionais (Apaes). Já a P4 trabalha há sete anos como intérprete e, desde maio de 2013, no AEE.

Já o ponto fulcral das experiências dessas professoras e as suas percepções quanto à formação inicial/continuada para atuação no AEE de certa forma são convergentes. Quanto à formação inicial, a P2 informou que fez um ótimo curso de Magistério (Nível Médio) entre 1994 e 1999. Esse curso oportunizou seu contato com a Educação Especial quando realizou estágio na Apae. Mas ela percebe a necessidade de participar de outros cursos para melhorar o seu atendimento na sala de recursos. Para a P3, a sua formação inicial (Normal Superior) e a sua experiência no trabalho na Apae em Minas Gerais contribuíram para o atendimento das crianças indígenas com deficiência, principalmente na parte da alfabetização. Porém, ela esclarece que tem dificuldade com surdez e paralisia cerebral. Em razão de sua formação em Pedagogia, a P1 disse ter facilidade em atender as crianças que estão nos primeiros anos do Ensino Fundamental. Mas tem dificuldade com as crianças dos últimos anos dessa etapa, porque esse trabalho requer o domínio de conhecimentos específicos (geografia, história e ciências).

Diante dessas constatações, percebe-se que os cursos de formação para o Magistério são globalmente idealizados segundo um modelo aplicacionista do conhecimento: os alunos passam alguns anos na universidade, aprendem conhecimentos proporcionais e ao se formarem vão para o mercado de trabalho. Nesse local, sentem-se sozinhos e percebem que os conhecimentos adquiridos não se aplicam a sua ação cotidiana (TARDIF, 2012).

Inclusive, o currículo da graduação interfere na competência do professor do AEE (CORTELAZZO, 2012). A formação inicial do professor precisa contemplar conhecimentos, habilidades e atitudes que the oportunizem um trabalho diferenciado e inclusivo com as crianças em situação de deficiência. Precisa compreender também as modalidades de Educação Especial e de Educação Indígena (entre outras), para que o professor seja qualificado para atuar nesses âmbitos. Geralmente, os cursos têm apenas certificado os professores com conhecimentos básicos, não potencializando áreas específicas. Quase sempre, os próprios docentes precisam aprimorar os seus conhecimentos específicos em futuras especializações ou em cursos de aperfeiçoamento.

Nóvoa (1997) ensina que a formação não se constrói por acumulação de cursos, mas por meio do trabalho de reflexividade crítica sobre as práticas e reconstrução permanente de uma identidade pessoal ${ }^{2}$. Assim, a formação docente e as experiências do trabalho corroboram na percepção da sua profissão. Nesse ponto, as interlocutoras desta pesquisa se sentem, de forma diferenciada, como professoras regentes e professoras do AEE. Todas concordam que estão satisfeitas com a escolha profissional de serem docentes. No entanto, na identificação com o exercício da função de docência do AEE, revelam descontentamentos e insegurança, causados por: a) formação inicial e continuada generalista; b) falta de apoio e incentivo por parte da gestão escolar e municipal; c) desconhecimento de certas peculiaridades da deficiência, em especial a deficiência intelectual e a paralisia cerebral; d) falta de recursos e de materiais didático-pedagógicos; e) dificuldade de obter parcerias com a área da saúde, assistência social e psicologia; f) barreiras linguísticas, uma vez que há alunos atendidos que são falantes da língua guarani.

Destaca-se também a iniciação dessas docentes no exercício do AEE e a sua preparação para o mesmo, bem como a identificação delas com esse trabalho. No primeiro ponto, todas as quatro foram convidadas pela Semed para trabalhar no AEE. Cabe ressaltar que a P1 foi a primeira professora do AEE das escolas indígenas e preparou as demais. A P1 fez o curso do governo federal, a P2 e a P3 fizeram uma formação continuada gerenciada pelo Neesp. Já a P4, por ter sido intérprete da aldeia e pesquisado surdez indígena, foi convidada a trabalhar na E4.

No segundo ponto, compreende-se a identificação como a "[...] criação de laços mais duradouros de vivência partilhada, o que por sua vez leva à construção coletiva de significados" (FRANCO; GENTIL, 2007). A P1 e a P4 disseram ter interesse em mudar de função. Pretendem voltar ao trabalho de intérpretes, pois pensam que possuem uma adequada competência para atuar nesse

\footnotetext{
2 Segundo Franco e Gentil (2007), a identidade "[...] apresenta traços afetivos, relaciona-se a valores, engendra-se a partir de possibilidades, de histórias coletivas, é fruto da relação coletiva com um sistema maior, mas, sobretudo, é fonte de referência e compreensão". Ela é "[...] um processo contínuo de construção individual e também coletivo, de caráter processual, auto-reflexivo e constituído a partir da definição de si mesmo e não como algo dado e estático" (FRANCO; GENTIL, 2007, p. 65).
} 
serviço. A P1 expôs seu objetivo de vida nestes termos: "Meu sonho é voltar a interpretar". Já a P2 e a P3 têm o objetivo de dar continuidade aos estudos no AEE. Elas revelam que suas insatisfações com o trabalho do AEE partem principalmente da necessidade de aprender novos conhecimentos e obter recursos, serviços e parcerias com outros setores.

Deduz-se que a formação realizada por essas professoras não consegue responder às necessidades de todas as crianças devido à proposta generalista da formação do professor para atuar no AEE. Isso instiga a compreender como as novas identidades das professoras estão sendo moldadas, apropriadas, transformadas nas escolas indígenas. As identidades são deslocadas, descentradas e fragmentadas, como fala Hall (2006). São também negociáveis e revogáveis ${ }^{3}$ (BAUMAN, 2005).

Nesse sentido, as identidades das professoras do AEE para escolas indígenas não são fixas e estáveis. São construídas pelas próprias professoras. Elas precisam traduzir culturalmente as suas experiências, com o objetivo de transitar nas fronteiras sociais e culturais. Para Bhabha (1998), o homem vive nos interstícios sociais (a sobreposição e o deslocamento de domínios da diferença), através dos quais as relações entre os indivíduos e interesses diversos são negociadas.

\section{CONSIDERAÇÕES FINAIS}

As professoras participantes dos encontros de formação, após análise das temáticas estudadas, da interação e da dinâmica do curso, bem como das reflexões registradas no diário de campo do pesquisador, opinaram que o programa proposto foi muito produtivo, pois oportunizou a participação efetiva e o amadurecimento profissional. Entende-se, assim, que as expectativas com relação à formação continuada proposta por esta pesquisa foram realizadas, porque trabalhou-se a partir de novas práticas de formação. De acordo com Nóvoa, "a formação passa pela experimentação, pela inovação, pelo ensaio de novos modos de trabalho pedagógico. E por uma reflexão crítica sobre a utilização. A formação passa por processos de investigação, diretamente articulados com as práticas educativas" (1997, p. 28).

Entretanto, a P2 e a P3 ressaltaram que a formação continuada poderia ter sido mais abrangente, com a participação de todas as professoras em todos os encontros, em vista da construção de um espaço de diálogo e crescimento coletivo. Também se compreende que a

\footnotetext{
3 "As 'identidades' flutuam no ar, algumas, de nossa própria escolha, mas outras infladas e lançadas pelas pessoas em nossa volta, e é preciso estar em alerta constante para defender as primeiras em relação às últimas. Há uma ampla probabilidade de desentendimento, e o resultado da negociação permanece eternamente pendente" (BAUMAN, 2005, p. 19).
}

frequência assídua das professoras poderia oportunizar novos projetos do AEE para as escolas indígenas.

As professoras também consideraram como ponto negativo a realização dos encontros fora da jornada de trabalho. Elas recomendaram que os próximos cursos fossem ofertados durante o expediente de trabalho, pois poderiam aprofundar melhor os conhecimentos discutidos. Inclusive, a P2 e a P4 sugeriram nos encontros da pesquisa que a formação continuada estivesse prevista no calendário de todas as escolas indígenas, o que corroboraria com a garantia da formação em serviço.

Vale notar que poucos encontros do programa de formação aconteceram durante a jornada de trabalho. Não foi possível realizar outros durante o expediente de serviço, porque não houve autorização dos gestores para que os atendimentos não fossem interrompidos.

Supõe-se que a formação de professores indígenas para o AEE encontra-se em "entre-lugares" e no contexto de novas identidades a serem negociadas. A presente pesquisa evidencia que uma política para esse tipo de formação é prioritária para a permanência com qualidade sociocultural das crianças indígenas com deficiência nas escolas indígenas. Trata-se de um padrão sociocultural que respeite as características e diretrizes da Educação Escolar Indígena.

Portanto, novas políticas de formação do professor para o contexto da diversidade devem ser propostas e repensadas. São necessárias diretrizes capazes de articular a educação inclusiva e intercultural. Partindo-se das bases dos conceitos da corrente Estudos Culturais, conclui-se que é preciso respeitar as lógicas e as ressignificações dos processos de hibridação cultural e dos saberes indígenas. A formação de professores do AEE para as escolas indígenas constitui-se em espaços fronteiriços (culturais e sociais) que interpelam o contexto educacional para sair em busca dos “entre-lugares". Essa formação implica traduções inesgotáveis de significado para as escolas indígenas. Além de contribuir para o diálogo intercultural entre as políticas educacionais e para a gestão educacional.

\section{REFERÊNCIAS}

BAUMAN, Zygmunt. Identidade: entrevista a Benedetto Vecchi. Rio de Janeiro: Jorge Zahar, 2005.

BHABHA, Homi K. O local da cultura. Belo Horizonte: UFMG, 1998.

BRASIL. Parecer CNE/CEB no 13, de 10 de maio de 2012. Assunto: Diretrizes Curriculares Nacionais para a Educação Escolar Indígena. Brasília, DF: MEC/CNE/CEB, 2012a.

. Resolução CNE/CEB no 5, de 22 de junho de 2012. Define Diretrizes Curriculares Nacionais para a Educação Escolar Indígena na Educação Básica. Brasília, DF: MEC/CNE/ CEB, 2012b. 
Política Nacional de Educação Especial na perspectiva da educação inclusiva. Brasília, DF: MEC/SEESP, 2008 .

Resolução n. 1, de 15 de maio de 2006. Institui Diretrizes Curriculares Nacionais para o Curso de Graduação em Pedagogia, licenciatura. Brasília, DF: MEC/CNE/CP, 2006.

Referenciais para a formação de professores indígenas. Brasília, DF: MEC, 2002.

Referencial Curricular Nacional para as Escolas Indígenas. Brasília, DF: MEC, 1998.

CORTELAZZO, B. de C. Formação de professores para uma educação inclusiva mediada pelas tecnologias. In: GIROTO, C. R. M.; POKER, R. B.; OMOTE, S. (org.). As tecnologias nas práticas pedagógicas inclusivas. Marília/SP: Cultura Acadêmica, 2012, p. 93-120.

COSTA DE SOUSA, Maria do Carmo da Encarnação. A organização do atendimento educacional especializado nas aldeias indígenas de Dourados/MS: um estudo sobre as salas de recursos multifuncionais para área da surdez. Dourados, 2013. Dissertação (Mestrado em Educação) - Faculdade de Educação, Universidade Federal Grande de Dourados, 2013.

FRANCO, M. E. D. P.; GENTIL, Heloisa Salles. Identidade do professor de ensino superior: questões no entrecruzar de caminhos. In: FRANCO, M. E. D. P.; KRAHE, E. D. (org.). Pedagogia universitária e áreas de conhecimento. Porto Alegre: EDIPUCRS, 2007, p. 39-58.

GARCÍA CANCLINI, Nestor. Culturas híbridas: estratégias para entrar e sair da modernidade. 4. ed. São Paulo: USP, 2008

GEERTZ, Clifford. A interpretação das culturas. 13. reimpr. Rio de Janeiro: LTC, 2008. Zahar, 2001.

Nova luz sobre a antropologia. Rio de Janeiro: Jorge

HALL, Stuart. A identidade cultural na pós-modernidade. 11. ed. Rio de Janeiro: DP\&A, 2006.

Da diáspora: identidade e mediações. Belo Horizonte: UFMG, 2003.

IBIAPINA, Ivana M. L. de M. Pesquisa colaborativa: investigação, formação e produção de conhecimentos. Brasília: Liber, 2008 (Série Pesquisa).

JESUS, Denise Meyrelles de; EFFGEN, Ariadna Pereira Siqueira. Formação docente e práticas pedagógicas: conexões, possibilidades e tensões. In: MIRANDA, T. G.; GALVÃO FILHO, T. A. (org.). O professor e a educação inclusiva formação, práticas e lugares. Salvador: EDUFBA, 2012, p. 17-24.
LACLAU, Ernesto. Emancipação e diferença. Rio de Janeiro: EDUERJ, 2011.

LIMA, Juliana Maria da Silva. Criança indígena surda na cultura guarani-kaiowá: um estudo sobre as formas de comunicação e inclusão na família e na escola. Dourados, 2013. Dissertação (Mestrado em Educação) - Faculdade de Educação, Universidade Federal da Grande Dourados, 2013.

MILANESI, Josiane Beltrame. Organização e funcionamento das salas de recursos multifuncionais em um município paulista. São Carlos, 2012. Dissertação (Mestrado em Educação Especial) - Centro de Educação e Ciências Humanas, Universidade Federal de São Carlos, 2012.

NÓVOA, António. Formação de professores e profissão docente. In: NÓVOA, A. (coord.). Os professores e a sua formação. 3. ed. Lisboa, Portugal: Dom Quixote, 1997, p. 15-34.

NOZU, Washington César Shoiti. Política e gestão do atendimento educacional especializado nas salas de recursos multifuncionais de Paranaíba/MS: uma análise das práticas discursivas e não discursivas. 2013. Dissertação (Mestrado em Educação) - Faculdade de Educação, Universidade Federal da Grande Dourados, Dourados, 2013.

QUEIROZ JÚNIOR, Edison de. Formação continuada de professores para o atendimento educacional especializado: desafios e perspectivas. São Paulo, 2010. Dissertação (Mestrado em Educação) - Faculdade de Educação, Universidade de São Paulo, São Paulo, 2010.

SILVA, João Henrique da. Formação de Professores para o Atendimento Educacional Especializado em escolas indígenas. 2014. Dissertação (Mestrado em Educação) Faculdade de Educação, Universidade Federal da Grande Dourados, Dourados, 2014.

SILVA SOUZA, Vânia P. da. Crianças indígenas kaiowá e guarani: um estudo sobre as representações sociais da deficiência e o acesso às políticas de saúde e educação em aldeias da região da Grande Dourados. 2011. Dissertação (Mestrado em Educação) - Faculdade de Educação, Universidade Federal da Grande Dourados, Dourados, 2011.

TARDIF, M. Saberes docentes e formação profissional. Petrópolis: Vozes, 2012.

WALSH, Catherine. Interculturalidade, crítica e pedagogia decolonial: in-surgir, re-existir e re-viver. In: CANDAU, Vera Maria (org.). Educação intercultural na América Latina: entre concepções, tensões e propostas. Rio de Janeiro: 7Letras, 2009 , p. 12-42.

Submetido em 28/08/2014 Aprovado em 28/12/2015 